Revista de E conomia Política, vol. 25, no 3 (99), pp. 163-189, julho-setembro/2005

\title{
U ma interpretação das causas da desaceleração econômica do Brasil ${ }^{1}$
}

\author{
EDM AR LISBOA BACHA2 \\ REGIS BONELLI
}

Accounting for Brazil's Growth Deceleration. The paper aims at explaining why Brazil's GDP growth plunged after 1980. Brazil's GDP grew at 7\% yearly from 1940 to 1980 but at only $2.5 \%$ per year since then. Increases in the relative price of investment that reduced the purchasing power of savings, associated to declines in the productivity of capital, seem to have been the most important factors behind the observed loss of dynamism. The tentative conclusion is that inward-oriented economic policies since the 1970s and, perhaps, even as early as the 1950s, had negative long-run growth implications that were aggravated by populist policies in the early years of the post-1984 redemocratization.

Key-words: Economic Growth; Capital Accumulation; Savings; R elative Price of the Investment; Capital Productivity.

JEL Classification: 047; 054

\section{INTRODUÇÃO}

Um mistério permeia a experiência brasileira de crescimento. Por que a taxa de crescimento do PIB diminuiu tão drasticamente desde 1980, depois de se manter em cerca de 7\% em média ao ano entre 1940 e 1980? Esse colapso do crescimento econômico brasileiro é resumido no Gráfico 1, que exibe as taxas anuais de

\footnotetext{
${ }^{1}$ A grademos os comentários de O livier Blanchard, R ogério W erneck e participantes em seminários na $C$ asa das $G$ arças e no IPEA, Rio de Janeiro. Erros remanescentes são de nossa inteira responsabilidade. Uma versão com apêndices metodológicos, tabelas e gráficos adicionais encontra-se no site da R evista de E conomia Política. Uma versão em inglês pode ser encontrada nos sites www.iepecdg.com e www.ecostrat.net/regis.html

${ }^{2}$ Instituto de Estudos de Política Econômica, Casa das Garças, Rio de Janeiro.

${ }^{3}$ ECOSTRAT Consultores e IPEA - Instituto de Pesquisa Econômica A plicada, Rio de Janeiro.
} 
crescimento do PIB de 1940 a 2002. Uma linha de tendência decenal é adicionada para ilustrar o agudo declínio da taxa de crescimento do país desde 1980.

Gráfico 1:Taxas de crescimento do PIB, (1940-2002)

e sua média móve de 10 anos (1949-2002)\%

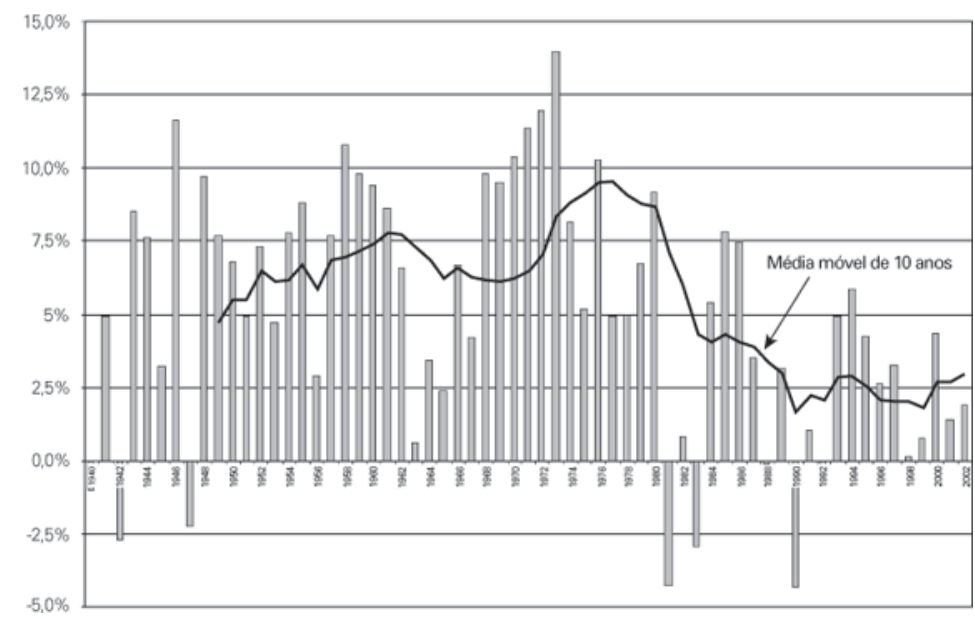

Este texto é parte de uma recente onda de interesse na análise da experiência brasileira de crescimento, conforme ilustrada pelos trabalhos de Bonelli e Fonseca (1998), Pinheiro et al. (2001), Bugarin et al. (2003), Pinheiro (2003), e Gomes, Pessoa e V eloso (2003). Sua característica distintiva é uma nova maneira de expressar a igualdade entre poupança e investimento como uma forma de organizar a contabilização do crescimento brasileiro. A Seção 2 provê uma breve resenha histórica do crescimento econômico brasileiro desde a 2 a Guerra, incorporando as descobertas do texto. A análise empírica começa na Seção 3, que exibe a associação entre o crescimento do PIB e a acumulação de capital prevista por dois modelos tradicionais de crescimento. A Seção 4 apresenta uma nova maneira de decompor a identidade entre poupança e investimento que leva em conta os múltiplos componentes da acumulação de capital. A Seção 5 mostra que a poupança, por si só, é insuficiente para explicar o colapso da acumulação de capital e do crescimento do PIB. As Seções 6, 7 e 8 argúem que, para uma descrição mais completa da acumulação de capital, é preciso levar em conta, além da poupança, as mudanças no preço relativo do investimento, na razão entre o produto e o capital-em-uso (ou produtividade do capital) e no grau de utilização da capacidade. A Seção 9 propõe uma taxonomia das fases de crescimento do país desde 1940 e discute decomposições alternativas do crescimento do estoque de capital e do PIB para essas fases, indicando, inter alia, os fatores responsáveis pelo colapso do crescimento econômico desde 1980. A Seção 10 conclui o trabalho e apresenta estimativas do potencial atual de crescimento do país. 0 A pêndice 1 revê brevemente os modelos $Y=A K$ e de Solow-Swan usados no texto, e o A pêndice 2 detalha os procedimentos para estimar o grau de utilização da capacidade. 


\section{ESQUEMA HISTÓRICO}

Para desvendar o mistério do colapso do crescimento brasileiro a partir de 1980 é preciso voltar ao início dos anos 1970, talvez até o começo dos anos 1950. Em ambas as ocasiões o país foi atingindo por choques adversos de termos de intercâmbio de longa duração - um choque do petróleo num caso, uma depressão dos preços do café no outro. As respostas de política para a escassez de divisas resultante poderiam ter reproduzido a dos países do sudeste asiático, focando um aumento da "exportabilidade" da economia - e assim reduzindo a dependência do país em relação às exportações de café nos anos 50 , e reforçando sua capacidade de pagar preços de petróleo mais elevados nos anos 70 . Um pessimismo sobre o potencial das exportações, associado com os interesses de grupos de cafeicultores e industrialistas voltados para a substituição de importações, impediu que isso acontecesse no início dos anos 50. A o contrário, a valorização do café e o protecionismo industrial mantiveram a dependência do país com relação às exportações de café e geraram um forte movimento de industrialização substitutiva de importações (ISI).

O período entre 1952 e 1955 foi crítico para a definição do padrão de industrialização que o Brasil passou a seguir desde então. Em 1952, o Presidente Vargas (1/51-8/54), sob a influência do M inistro da Fazenda H orácio Lafer (2/516/53), reinstalou a política de valorização do café do pré-guerra, como uma forma de defender uma taxa de câmbio que se tornara supervalorizada com o fim do boom da Guerra da Coréia. Em 1953, o M inistro da Fazenda O swaldo A ranha (6/53-8/54) instituiu o sistema de câmbio múltiplo como uma forma de privilegiar as importações "essenciais", definidas como aquelas sem similar nacional. Para apoiar o movimento em prol da industrialização, criou-se um banco nacional de desenvolvimento (BN DE) em 1952 e instituiu-se o monopólio estatal de petróleo (Petrobrás) em 1953.

0 conservador Vice-Presidente Café Filho (8/54-11/55) assumiu a presidência depois do suicídio de Vargas em agosto de 1954. Seu M inistro da Fazenda, Eugênio Gudin (8/54-4/55), tentou desfazer o esquema de valorização do café, mas foi forçado a renunciar. Seu sucessor, José M aria Whitaker (4/55-10/55), tentou desmantelar o sistema de câmbio múltiplo de Aranha, somente para ser demitido também. 0 próprio Presidente Café Filho também foi destituído, no chamado anti-golpe democrático de novembro de 1955.

Com a eleição do Presidente Juscelino Kubitschek (1956-60), o jogo terminou e o Brasil embarcou numa trajetória de industrialização substitutiva de importações que iria durar até os anos 1980. N esse processo aumentou substancialmente 0 custo relativo do capital enquanto, a partir de meados da década de 1970, diminuía a produtividade do capital. Uma qualificação, todavia, aplica-se aqui: processos de produção mais intensivos em capital foram adotados no mundo inteiro, em resposta aos choques de petróleo do início dos anos 1970, em conseqüência do qual a produtividade do capital declinou no mundo como um todo, ainda que menos do que no Brasil. Peculiar ao Brasil foi a associação de tal declínio com um forte aumento no preço relativo dos bens de investimento. 
0 protecionismo industrial sob a presidência de Kubitschek esteve associado com a promoção do investimento estrangeiro direto. Isto aumentou a taxa de absorção do progresso técnico e logrou manter o impulso de crescimento herdado dos anos 1940. A convulsão política, associada a uma inflação em aceleração no início da década de 60, interrompeu temporariamente este processo. 0 s tecnocratas que ascenderam ao poder com o golpe militar de 1964 conseguiram estabilizar a economia, enquanto introduziam reformas impositivas e financeiras significativas. 0 boom de poupança e investimento que resultou, associado a uma alta taxa de progresso técnico, ficou conhecida como o "milagre econômico brasileiro" do período 1965-74.

$\mathrm{N} o$ início dos anos 1970, uma economia superaquecida foi atingida pelo choque do petróleo. A obsessão com a legitimação de um regime autoritário estatizante através do sucesso econômico de curto prazo determinou uma ênfase renovada em substituição pesada de importações, financiada por uma forte acumulação de dívida externa. 0 ponto crítico definidor do futuro econômico do Brasil foi a decisão do general Geisel (1974-79) de enfrentar o choque do petróleo de 1973 dobrando a aposta numa substituição de importações superpesada. Isso só pôde ser colocado em prática através de uma dependência profunda na reciclagem financeira internacional dos petrodólares. Com o benefício do conhecimento da história, essa foi uma decisão desafortunada, porque o cenário internacional deteriorou-se continuamente a partir do final dos anos $70 . \mathrm{N}$ a economia doméstica, uma indexação salarial aperfeiçoada acompanhou a abertura do regime militar que foi iniciada pelo mesmo general G eisel e levada adiante pelo general Figueiredo (1979-85). D emanda doméstica excessiva e indexação de preços e salários levaram a dívida externa e a inflação doméstica a aumentarem fortemente. 0 preço relativo do investimento aumentou e a produtividade do capital declinou substancialmente entre 1974 e 1984. Esse período foi também caracterizado por "regressão" técnica ao invés de progresso técnico. Uma adversidade internacional continuada eventualmente forçou o país a declarar uma moratória nas suas obrigações externas no final de 1982.

A crise financeira do início dos anos 1980 pôs um ponto final tanto no regime militar como no crescimento forçado do país. 0 retorno do país à democracia em 1985 ocorreu sob uma pesada dívida externa e uma inflação em aceleração. A euforia política com a redemocratização, acelerada pelo sucesso de curto prazo de um congelamento de preços e salários em 1986, obscureceu as ineficiências econômicas herdadas do regime militar. Isto alimentou uma seqüência de choques "heterodoxos" fracassados de estabilização e moratórias de dívida, enquanto uma nova Constituição populista era promulgada em 1988 - assim tornando o país praticamente ingovernável. As moratórias da dívida começaram para valer quando o $\mathrm{M}$ inistro da Fazenda D elfim $\mathrm{N}$ etto (1968-74) e posteriormente do Planejamento (1979-84) subestimou fortemente, através de uma prefixação, a correção monetária da dívida interna em 1980 . V eio em seguida a reestruturação da dívida externa de dezembro de 1982, levada a cabo pelo mesmo ministro. A pós isso, o Presidente Sarney (1985-89) implantou três sucessivos "choques he- 
terodoxos de estabilização" que suprimiram temporariamente a correção monetária da dívida interna. No começo de 1987, Sarney declarou uma moratória unilateral da dívida externa. A maior moratória da dívida interna de todas foi o congelamento por um ano de praticamente todos os ativos financeiros domésticos no início do governo de Collor (1990-92).

A hiperinflação se manifestou, mas foi finalmente dominada pelo Plano R eal, de 1994. Isto abriu caminho no governo do Presidente Cardoso (1995-2002) para um desvio radical do modelo estatizante de substituição de importações que prevaleceu no regime militar. $M$ as uma política fiscal frouxa e uma dependência excessiva na âncora cambial (o que demandou o apoio de altas taxas reais de juros) não favoreceram as exportações nem o investimento privado, impedindo assim que uma retomada sustentada do crescimento tivesse lugar. D epois de uma crise cambial que culminou em janeiro de 1999, um tripé de política macroeconômica mais sensato foi adotado: um superávit fiscal primário elevado, uma política monetária de metas de inflação e uma taxa de câmbio flutuante. As reformas estruturais do governo Cardoso conseguiram fazer parar os processos de longo prazo de aumento do preço do investimento e de declínio da produtividade do capital, enquanto aumentavam o grau de utilização da capacidade sem acelerar a inflação. 0 progresso técnico voltou a se manifestar, mas isso não foi suficiente para gerar crescimento sustentado, mesmo depois de 1999, porque a acumulação de capital se viu contida por uma sucessão de choques adversos: 0 estouro da bolha do $\mathrm{N}$ asdaq, a crise energética interna, 11 de setembro, a moratória da Argentina e o espectro de uma presidência esquerdista de Lula.

Em seus primeiros anos de governo, em lugar de tentar um retorno populista ao modelo estatizante de economia fechada do passado, como muitos temiam, o Presidente Lula manteve intacto o tripé de política macroeconômica pós-1999. Também continuou a reformar o contorcido edifício legal erigido pela Constituição de 1988. A economia recuperou-se em 2004, mas a sustentação de um crescimento econômico continuado ainda é um ponto de interrogação.

Com esse pano de fundo, as próximas seções desenvolvem um esquema contábil para o crescimento econômico com o propósito de dar substância às interpretações acima e também de permitir uma avaliação do atual potencial de crescimento do país.

\section{O CRESCIMENTO DO PIB CORRELACIONA-SE COM A ACUM ULAÇÃO DE CAPITAL}

A acumulação de capital é uma candidata natural para começar a explicação do crescimento brasileiro. No chamado "modelo $Y=A K$ ", a acumulação de capital é o único fator responsável pelo crescimento do $\mathrm{PIB}^{4}$. N um mundo de So-

${ }^{4} \mathrm{~A}$ forma reduzida do modelo AK é indistinguível da do tradicional modelo de crescimento de $\mathrm{H}$ arrod-D omar. 
low-Swan (SS), a acumulação de capital partilha essa responsabilidade com o trabalho efetivo, ao longo de um processo de ajustamento em direção a um estado de crescimento equilibrado possivelmente cambiante 5 . Conforme se vê no Gráfico 2, o pressuposto de que o crescimento do PIB correlaciona-se com a acumulação de capital encontra apoio nos dados brasileiros ${ }^{6}$.

Gráfico 2: Taxas de crescimento do PIB e do estoque de capital, 1941-2002

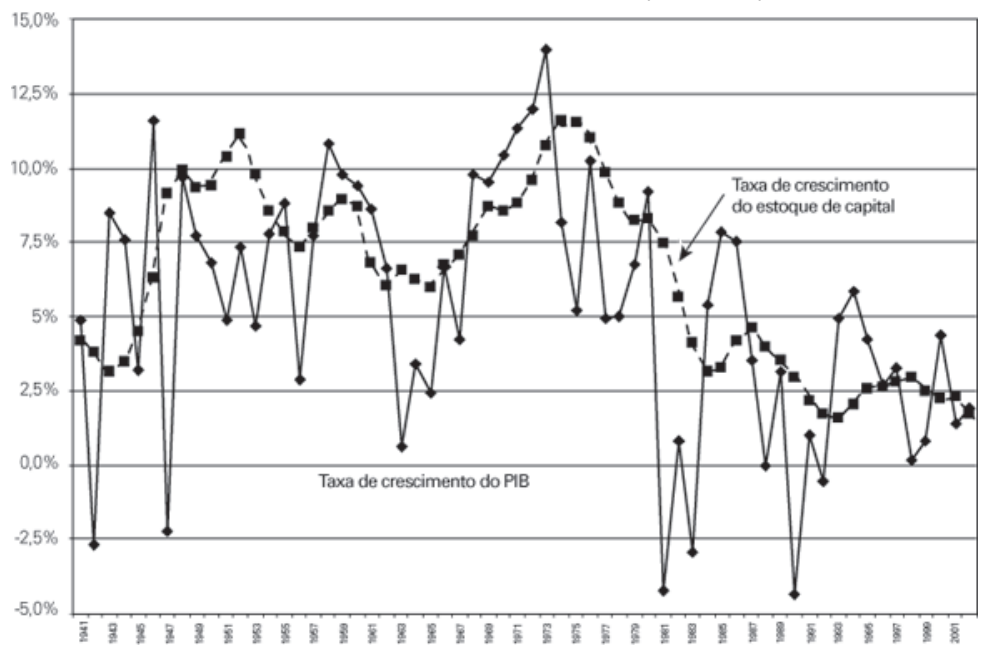

O Gráfico 2 mostra as taxas de crescimento do estoque de capital juntamente com as do PIB. Uma associação positiva é aparente entre as duas séries. Em particular, a depressão do crescimento do PIB desde 1980 é acompanhada por um colapso similar da acumulação real de capital. A tendência do PIB é, assim, bem capturada pela evolução do estoque de capital. M as o Gráfico 2 também indica que a taxa anual de crescimento do PIB é bem mais volátil do que a do estoque de capital. Isso é de esperar, em vista dos componentes cíclicos e irregulares da série de PIB, bem como da inércia associada a mudanças nas relações entre fluxos de investimento e estoques de capital. O conceito de capital-em-uso é introduzido para levar em conta tais flutuações. Ele é obtido pela multiplicação do

\footnotetext{
${ }^{5} \mathrm{O}$ A pêndice 1, encontrável na versão disponível na internet, contém uma breve resenha dos modelos Y = AK e de Solow. Usando o conjunto de dados da Penn W orld Table, Bernanke e Gürkaynak (2001) descobriram que a implicação de um modelo AK simples, onde as taxas de crescimento dos países dependem das respectivas taxas de poupança (aproximada pela taxa de investimento real), é mais consistente com os dados do que o suposto do modelo de Solow-Swan que o crescimento é exógeno.

${ }^{6} \mathrm{~N}$ osso sistema de Contas N acionais começa em 1947. Dados para anos anteriores são disponíveis, mas com qualidade variável, especialmente no que concerne aos deflatores de preços. Lucilene M orandi graciosamente nos forneceu os dados de 1940 até 1946, bem com toda a série do estoque de capital. Essa série foi por ela construída com base num método de inventário perpétuo, de forma consistente com as séries de investimento real nas Contas $\mathrm{N}$ acionais. Para detalhes, veja-se $\mathrm{M}$ orandi e Reis (a sair). D evido à inexistência de deflatores de preços apropriados antes de 1947, os dados de estoque de capital são mais confiáveis a partir de meados dos anos 60 .
} 
estoque de capital pelo grau de utilização da capacidade, calculado conforme será explicado na Seção 8.

A correlação entre o crescimento do PIB e o crescimento do capital-em-uso é muito alta $(R=0,83)$. Isto confirma que a acumulação de capital é de fato um bom ponto para começar uma análise do crescimento do PIB. Tendo em conta que mais tarde teremos que incorporar o emprego e o progresso técnico na análise, começaremos a discussão do crescimento brasileiro focando os determinantes da taxa de crescimento do estoque de capital.

\section{CONTABILIZANDO INTEGRALMENTE A ACUM ULAÇÃO DE CAPITAL}

O ponto de partida é a expressão:

$K^{\prime}=I / K-\delta$

onde $K^{\prime}$ é a taxa de crescimento do estoque de capital, I é o investimento bruto real, $K$ é o estoque de capital existente, e $\delta$ taxa de depreciação.

A relação entre $o$ investimento bruto real e o estoque de capital $(I / K)$ pode ser escrita como o produto da taxa de investimento real bruto $(I / Y)$ com a relação produto capital $(\mathrm{Y} / \mathrm{K})$ :

$\mathrm{I} / \mathrm{K}=(\mathrm{I} / \mathrm{Y}) \cdot(\mathrm{Y} / \mathrm{K})$

A taxa de investimento real bruto $(I / Y)$, por sua vez, é exatamente igual ao produto da taxa nominal de poupança pelo inverso do preço relativo do investimento:

$I / Y=\left(P_{i} / / P_{y} Y\right) \cdot\left(P_{y} / P_{i}\right)=\left(S / P_{y} Y\right) \cdot\left(P_{y} / P_{i}\right)=s \cdot(1 / p)$

onde a primeira igualdade é somente um expediente para introduzir a taxa de investimento nominal $\left(\mathrm{P}_{\mathrm{i}} \mathrm{l} / \mathrm{P}_{\mathrm{y}} \mathrm{Y}\right)$, e assim poder fazer uso da igualdade entre poupança nominal e investimento nominal na segunda igualdade 7 . A terceira igualdade é meramente uma conseqüência das definições de $S=S / P_{y} Y$ e de $p=P_{i} / P_{y}$.

A razão produto-capital $(\mathrm{Y} / \mathrm{K})$ pode ser escrita como o produto da taxa de utilização da (u) pela relação entre o produto e o capital-em-uso (v):

$\mathrm{Y} / \mathrm{K}=\mathrm{u} .(\mathrm{Y} / \mathrm{uK})=\mathrm{u} . \mathrm{v}$

Substituindo (3) e (4) em (2) e o resultado em (1), finalmente obtemos:

$\mathrm{K}^{\prime}=\mathrm{s} .(1 / \mathrm{p}) \cdot \mathrm{u} . \mathrm{v}-\delta$

A equação (5) mostra que o impacto da taxa de poupança (s) na taxa de crescimento do estoque de capital ( $\left.K^{\prime}\right)$ é condicionado pelo preço relativo do investimento $(p)$, pelo grau de utilização de capacidade $(u)$, e pela relação entre o produto e o capital-em-uso (v), ou produtividade do capital. A taxa de depreciação (d) também precisa ser levada em conta - exceto pelo fato de que, como ela va-

\footnotetext{
7 Só recentemente as variações de estoque começaram a ser calculadas nas Contas $\mathrm{N}$ acionais. $\mathrm{N} \mathrm{a}$ maior parte das séries, as variações de estoque estão incorporadas ao consumo privado. Por essa razão, para a série como um todo definimos a poupança bruta como sendo igual ao investimento fixo nominal bruto. Como nas Contas $\mathrm{N}$ acionais a poupança continua a ser estimada como um resíduo, a igualdade entre poupança e investimento se dá sem qualquer discrepância estatística.
} 
ria somente entre 0,038 e 0,040 nas séries que usamos, não contribui para explicar as mudanças na acumulação de capital ao longo do tempo.

As correlações entre as séries de crescimento do PIB $\left(\mathrm{Y}^{\prime}\right)$ e as séries para $\mathrm{K}^{\prime}, \mathrm{V}$, u, p e s em 1941-2002 e 1952-2002 (este segundo período é selecionado porque, como argüimos na Seção 2, 1952 foi um ponto de virada crítico na experiência de crescimento brasileiro) indicam associações bastante ilustrativas entre as principais variáveis analisadas ${ }^{8}$. 0 coeficiente de correlação entre $Y^{\prime}$ e K' é 0,52 em 19412002 e 0,60 em 1952-2002. Em ambos os períodos, o grau de utilização de capacidade (u) é a variável com a relação mais estreita com a taxa de crescimento do PIB ( $R=0,70$ e 0,74, respectivamente em 1941-2002 e 1952-2002). O s próximos na fila são o preço relativo do investimento, $p(R=-0,53 e-0,59$, respectivamente), e a relação entre o produto e o capital-em-uso, $v(R=0,37$ e 0,59 , respectivamente).

Surpreendentemente, a taxa de poupança s é correlacionada negativamente (ainda que de forma não significativa, na maior parte dos casos) com todas as variáveis relacionadas ao crescimento. De forma também interessante, $p$ e $v$ estão entre as variáveis com a correlação mais estreita nas séries estatísticas $(R=-0,68$ em 1941-2002 e um surpreendente - 0,92 em 1952-02), vindo em seguida as correlações entre K' e p. A próxima seção tenta decifrar as implicações de tais associações para o comportamento histórico da taxa de crescimento do estoque de capital.

\section{A POUPANÇA SOZINHA NÃO EXPLICA \\ O COLAPSO DO CRESCIMENTO}

A poupança seria uma candidata óbvia para explicar o colapso da acumulação de capital desde 1980. 0 Gráfico 3 exibe o comportamento tanto da taxa de poupança total (doméstica mais externa) como da poupança doméstica (poupança doméstica bruta como proporção do PIB nominal) de 1940 a 2002. A poupança doméstica é obtida como um resíduo a partir da poupança total após dedução da poupança externa, contabilização cuja pode ter variado ao longo do tempo. Privilegiaremos uma análise baseada na poupança total (doméstica + externa) e em geral deixaremos de lado a série para a poupança doméstica.

\footnotetext{
${ }^{8}$ U ma tabela com essas correlações encontra-se na versão deste artigo disponível no site da REP na internet.
} 


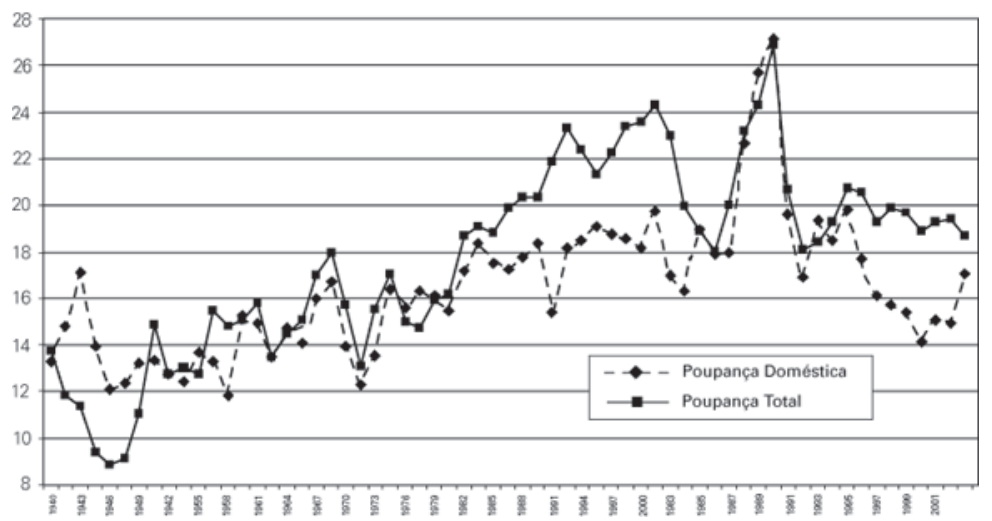

Com pouca flutuação, a taxa de poupança total é em média de cerca de $15 \%$ do PIB de 1947 até 1965. Ela escala para quase $24 \%$ em 1980, e então diminui para cerca de $19 \%$ daí em diante - com um incrível pico durante o período hiperinflacionário de 1987-89, quando ela atinge uma média de $24,8 \%$. 0 desvio de comportamento da taxa de poupança doméstica em 1987-89 parece contrariar as realidades econômicas desse período turbulento: um tempo em que a poupança do governo contraiu-se e a inflação acelerou-se. É difícil acreditar que em tais circunstâncias a taxa de poupança doméstica tenha aumentado para $27 \%$ do PIB em 1989 a partir do nível relativamente estável de 19\% observado de 1970 até 1986, somente para cair novamente para o mesmo 19\% relativamente estável no período subseqüente de 1990-93! Um erro de medida da poupança nominal em 1987-89 é sugerido por este comportamento. Testar essa hipótese requereria uma avaliação detalhada das séries de preço subjacentes às Contas $\mathrm{N}$ acionais a preços correntes do período. Isso é tarefa para o futuro. Por enquanto, aceitaremos a série de poupança tal como ela aparece nas $\mathrm{C}$ ontas $\mathrm{N}$ acionais.

O s movimentos da taxa de poupança total são fortes, mas têm pouca relação com o colapso da formação de capital depois de 1980. Essa falta de associção é documentada por um coeficiente de correlação (não significativo) de $R=-0,02$ entre o crescimento do estoque de capital e a taxa de poupança total no período 1941-2002. Uma inspeção mais detida dos dados, contudo, sugere que uma quebra estrutural parece ter ocorrido após o início dos anos 1980 na relação entre as taxas de poupança e de crescimento do estoque de capital: coeficientes de correlação de 0,66 e 0,64 entre essas duas variáveis foram encontrados para os períodos de 1941-80 e 1981-2002, respectivamente. Isto indica que existe al guma associação. M as depois de 1980 a mesma taxa de poupança parece gerar menos crescimento do estoque de capital do que antes desse ano.

A ssim, a aparente falta de associação entre a acumulação de capital e a taxa de poupança para o período como um todo não significa que a taxa de poupança não importe para a acumulação de capital; mas sim que a poupança, por si 
mesma, não consegue explicar o colapso na taxa de crescimento do PIB a partir de 1980. As próximas seções investigam quais variáveis parecem estar entupindo o canal de transmissão da poupança para a acumulação de capital e o crescimento do PIB no Brasil desde 1980.

\section{AUM ENTO SUSTENTADO DO PREÇO RELATIVO DO IN VESTIM ENTO}

O Gráfico 4 mostra o extraordinário comportamento do preço relativo do investimento entre 1950 e 2000, definido como a razão entre o deflator de preços do investimento fixo bruto e o deflator de preços do PIB ${ }^{9}$. 0 mesmo Gráfico 4 mostra a evolução em 1950-2000 de uma variável similar: a média mundial do preço relativo do investimento a preços de dólar internacional, também do projeto PWT.

Gráfico 4: Preço relativo do investimento: Brasil e mundo, 1950-2000

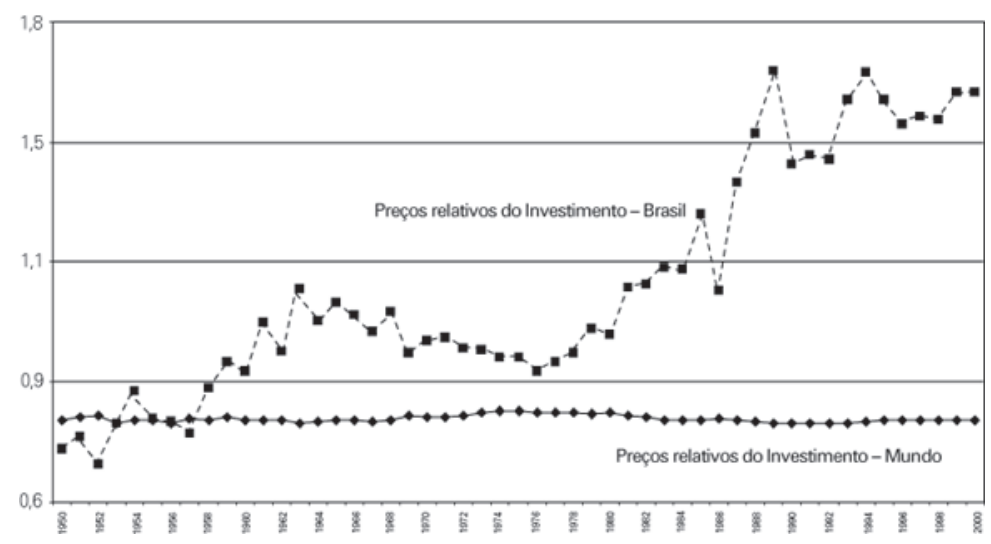

Em termos gerais, o preço relativo do investimento no Brasil aumenta rapidamente entre o começo dos anos 1950 e meados dos anos 1960. Então, cai um pouco até meados dos anos 1970 . Posteriormente, ele aumenta muito rapidamente, a um ponto tal que, no começo dos anos 1990, p é mais do que o dobro do valor no começo dos anos $1950^{10}$. O preço relativo de máquinas e equipamentos (não mostrado) replica o padrão do preço relativo do investimento, exceto por flutuações mais amplas, que provavelmente estão associadas a mudanças nos pre-

\footnotetext{
${ }^{9}$ Esses dados são do projeto das Penn World Tables (PWT 6.1) de H eston, Summers e A tten (2002), e não exatamente iguais àqueles diretamente derivados das contas nacionais brasileiras. Contudo, 0 coeficiente de correção entre as duas séries de preços é muito alto, $R=0,962$. N as Penn W orld Tables, o numerário para todos os índices de preços em todos os anos é o deflator to PIB dos EUA.

${ }^{10}$ Para uma análise prévia do comportamento do preço relativo dos bens de investimento no Brasil, veja-se D. Carneiro e R. W erneck (1993).
} 
ços de maquinaria importada em alguns períodos, devido a movimentos da taxa de câmbio real e mudanças na política de comércio exterior.

0 aumento do preço relativo do investimento é uma anomalia brasileira numa perspectiva mundial. A média mundial do PWT para esta relação de preços permanece relativamente constante no período 1950-2000, como se indica no Gráfico 4. Explicações possíveis para o aumento do preço relativo do investimento no Brasil incluem as seguintes:

1. aumento do poder de oligopólio em indústrias produzindo tanto bens finais como bens intermediários de investimento (como o cimento);

2. ineficiências no processo de produção de bens de capital, na medida em que cada vez mais bens previamente importados são produzidos domesticamente;

3. maior demanda por bens duráveis, incluindo habitações, como uma proteção contra a hiperinflação e os riscos de moratória financeira, com reflexos no preço relativo de tais bens se a curva de oferta for inclinada positivamente - uma hipótese sugerida por Bugarin et al. (2003);

4. comportamento defensivo de preços dos oligopolistas, face a atrasos no pagamento de compras governamentais, num contexto de inflação em aceleração ${ }^{11}$;

5. erros de medida de índices de preços, conforme sugerido por Pinheiro (2003). Isso viria na forma de uma superestimativa dos aumentos dos preços relativos dos bens de investimento, particularmente durante o período hiperinflacionário de 1987-89.

O s fatores 1 e 2 podem ter operado mais fortemente até o início dos anos 1980. O s fatores 3 a 5 podem ter-se tornado importantes quando a inflação saiu de controle a partir de meados dos anos 80 . Contudo, o preço relativo dos bens de investimento não caiu substancialmente depois da estabilização de preços em 1994, o que sugere erro de medida ou custo relativo (acrescido de poder de mercado), e não a demanda especulativa, o que explica o comportamento desta variável desde 1980. A lém disso, demanda especulativa (ou de precaução) por bens duráveis deviam afetar os preços dos bens de capital instalados, não necessariamente o custo dos novos bens de investimento, que são objeto de nossa análise.

Uma avaliação do comportamento da relação entre o produto e o capitalem-uso nos ajudará a compreender melhor a evolução de p.

\footnotetext{
${ }^{11}$ O s deflatores de preços dos bens de investimento nas contas nacionais brasileiras são derivados dos índices de preços por atacado e de custo da construção da Fundação G etúlio Vargas. Esses são freqüentemente derivados de preços de "lista" obtidos de uma amostra de firmas. Para bens duráveis, que são normalmente vendidos a crédito, tais preços de "lista" podem ter incorporado prêmios crescentes tanto com a inflação como com os atrasos de pagamentos nas compras governamentais.
} 


\section{PRODUTIVIDADE DO CAPITAL DECRESCENTE}

0 comportamento da relação entre o produto e o capital-em-uso (v) no período de 1940-2002 ${ }^{12}$ registra uma tendência declinante desde o imediato pós- $2^{\text {a }}$ Guerra até o princípio dos anos $1990^{13}$. Em mais detalhe: começando de um nível elevado de mais do que 0,6 no começo dos anos 1940, a relação produto capital-em-uso aumenta durante a Guerra e então declina continuamente até o começo dos anos 1950, para cerca de 0,5. Daí até meados dos anos 1970, v flutua em torno de uma tendência ligeiramente negativa. 0 próximo estágio é uma forte contração de v, começando em 1973 e somente tendo uma pausa em 1983, com $v$ reduzindo-se para algo em torno de 0,36 . Um pequeno declínio ocorre depois de 1987, até que $v$ se estabiliza em cerca de 0,34 desde o início dos anos 1990 (média de 1992-2002). Tais épocas são em geral consistentes com a experiência de industrialização brasileira: substituição leve de importações durante a Guerra e até meados dos anos 1950; substituição de importação de bens duráveis de consumo no final dos anos 1950 e nos anos 1960; substituição pesada das importações de bens de capital e produtos intermediários desde o início dos anos 1970 até o princípio dos anos 1980.

Três hipóteses alternativas são sugeridas para explicar o declínio de v, a saber:

1. um declínio na relação produto-capital pode ser esperado na medida que uma economia se move de um estágio predominantemente rural (como o Brasil até a década de 1930) para escalar na direção de uma economia industrial madura. Esta tendência pode ter sido acentuada por características específicas da industrialização brasileira: um processo de substituição de importações altamente protegido, acompanhando de um padrão de industrialização oligopolista com forte presença de empresas públicas;

2. a experiência brasileira pode estar simplesmente refletindo uma tendência mundial mais geral de relações produto-capital declinantes;

3. finalmente, num mundo de Solow-Swan, a relação produto-capital não é um dado técnico, e pode declinar porque está convergindo para um vaIor de equilíbrio estacionário mais baixo, de forma consistente, por exemplo, com um aumento duradouro da taxa de poupança.

Consideremos essas três hipóteses de forma sucessiva.

7.1 Culpado por associação: os preços relativos aumentam à medida que a produtividade cai. 0 Gráfico 5 reforça a conjectura de que a trajetória de substituição de importações escolhida pelo país a partir do início dos anos 1980 pode estar por trás do comportamento observado das séries. Trata-se de um diagrama de dispersão, com a relação produto/capital-em-uso no eixo horizontal e o preço relativo do investimento no eixo vertical.

\footnotetext{
${ }^{12}$ Conforme explicado anteriormente, a série de estoque de capital é de M orandi e R eis (a sair); a série de $u$ é derivada no A pêndice 2 . A razão $v$ foi obtida pela divisão do PIB real (a preços constantes de 2000), Y, pelo estoque real de capital em uso, u.K

${ }^{13} \mathrm{O}$ gráfico com essa tendência encontra-se na versão disponível no site da REP na internet.
} 
Gráfico 5: Correlação negativa entre v e p desde 1952

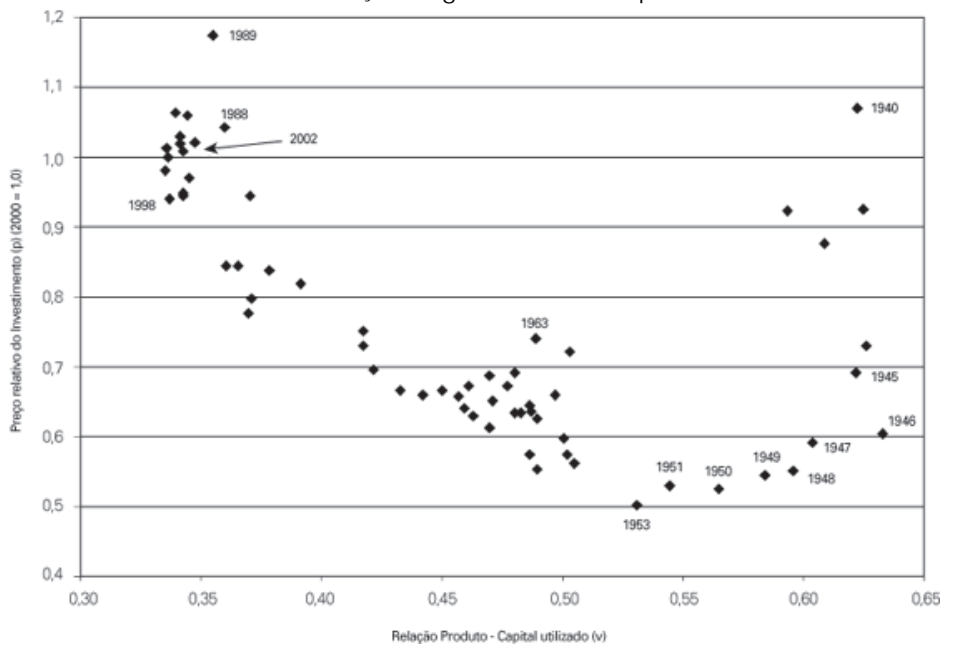

A partir do início dos anos 1950, acompanhando as decisões de política econômica mencionadas na Seção 2 no sentido de aprofundar o processo de substituição de importações, o preço relativo do investimento e a relação produto/capital-em-uso apresentam uma correlação negativa: na medida em que o primeiro cresce, a segunda cai, continuamente até o início dos anos 1990.

A propósito, o Brasil tem o pior comportamento numa lista de 63 países com dados para 1960-2000, obtida do PW T 6.1, no que se refere à combinação de aumentos do preço relativo do investimento $\left(p^{\prime}\right)$ com correlação $(R)$ positiva entre o preço relativo do investimento e a razão produto-capital. Para o Brasil esse par é $\left(p^{\prime}=168,7 \%\right.$; $\left.R=0,90\right)$. Em seguida ao Brasil vêm Venezuela ( $p^{\prime}=118,5 \%$; $R=0,87)$, Israel $\left(p^{\prime}=111,9 \% ; R=0,80\right)$, Iran $\left(p^{\prime}=84,0 \% ; R=0,51\right)$, G récia ( $\left.p^{\prime}=70,4 \% ; R=0,95\right)$, e Cingapura $\left(p^{\prime}=69,2 \% ; R=0,94\right)$.

Para ajudar a fixar a idéia sobre uma possível seqüência de causalidade, imagine-se uma economia de um só setor inicialmente produzindo bens de consumo tanto para uso doméstico como para exportar, e importando bens de capital para expandir a capacidade produtiva. Introduza-se nesta economia um setor produtor de bens de capital (relativamente ineficiente) para o qual, na margem, são desviados cada vez mais bens de consumo que poderiam ser exportados, em troca de bens de investimento produzidos domesticamente. $\mathrm{N}$ a medida em que 0 tamanho do desvio cresce, a produtividade total cai, mas isso pode ser temporariamente ocultado se a introdução do setor produtor de bens de capital é acompanhada por um esforço adicional de poupança. É isso o que parece ter acontecido no Brasil. Como mostrado no Gráfico 3, a taxa de poupança total aumentou para $20 \%$ do PIB no começo dos anos 1970 , vindo de cerca de $15 \%$ do PIB nos anos 1950, com uma ampla ajuda da poupança externa. Conjuntamente com um melhor uso da capacidade instalada, isto foi mais do que suficiente para produzir o "milagre econômico brasileiro" da primeira parte do regime militar (1964 até 1974). N a segunda parte do regime militar, de 1974 até 1984, em seguida à decisão do governo de aprofundar o processo de substituição de importações sob 
condições externas extremamente adversas, a relação produto/capital-em-uso declinou $24 \%$, enquanto que o preço relativo do investimento aumentou $33 \%$.

7.2 C ausalidade internacional: uma tendência mundial para uso mais intensivo do capital. O Gráfico 6 compara a evolução da relação produto-capital no Brasil com uma média simples da relação produto-capital para uma amostra de 83 países no período 1950-200014. A evolução da relação produto-capital do Brasil coincide amplamente com a da média mundial, que também declina no período pós-1970, possivelmente como uma reação ao choque do petróleo. Além disso, a relação para o Brasil é sempre menor do que a média mundial, exceto no período 1967-73. Esses resultados são apenas sugestivos, porque os dados de estoque de capital baseados na PWT somente podem ser usados com mais confiança a partir de $1970^{15}$. M esmo assim, eles indicam que o Brasil não foi muito diferente do resto do mundo na evolução histórica da relação produto-capital.

Gráfico 6: Relações produto-capital, Brasil e Mundo, 1950-2000

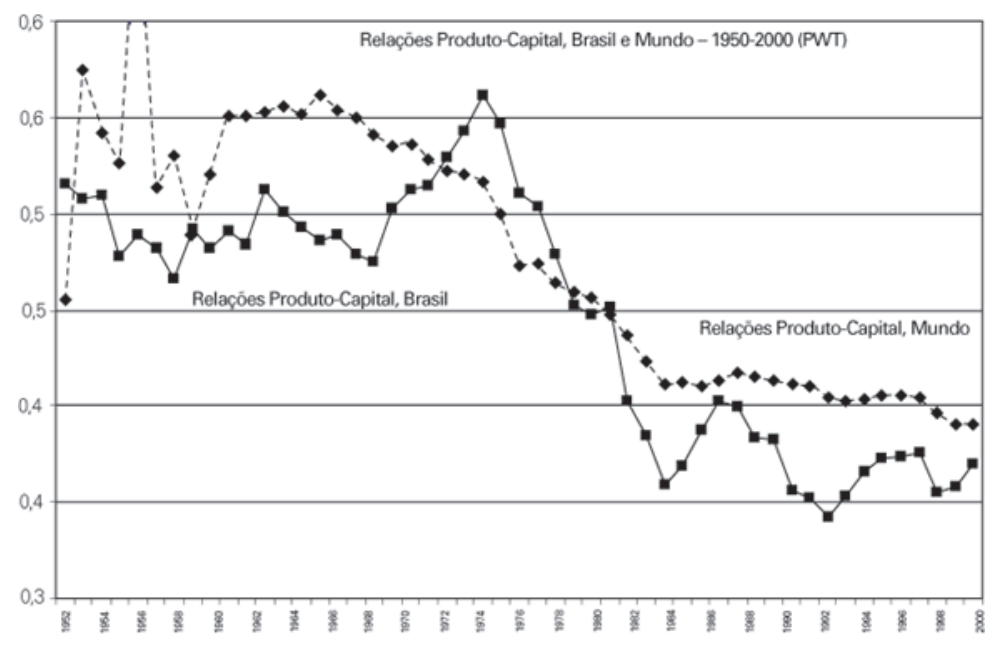

7.3 Convergência para um estado estacionário de Solow-Swan. Um resultado conhecido do modelo de Solow-Swan é que se a relação produto-capital não

\footnotetext{
${ }^{14}$ Samuel Pessoa gentilmente nos forneceu suas séries para as relações produto-capital desses 83 países, baseadas nos dados da PWT (cf. Gomes et al., 2003). Como essas séries não são ajustadas pelo grau de utilização da capacidade, também usamos as séries de Pessoa para o caso brasileiro. Assim, estritamente falando, as séries mostradas no G ráfico 7 são, na terminologia deste estudo, não para "v" mas sim para "v.u." . A demais, os dados de Pessoa para 1950-59 compreendem apenas 47 países. Usamos a razão entre a relação produto-capital média dessa sub-amostra para aquela da amostra completa de países em 1960 para corrigir os dados de 1950-59 e assim impedir a série de dar um pulo quando a amostra completa foi introduzida, a partir de 1960.

${ }^{15} \mathrm{G}$ omes et al. (2003) usaram um estoque de capital simulado para 1950 (ou 1960, dependendo do país) e então completaram as séries aplicando um método de estoques perpétuos nos dados do PWT para o investimento a preços constantes daí em diante.
} 
é constante ela está convergindo para seu valor de estado estacionário. Para obter esse valor, observe-se que a taxa de crescimento estacionário do estoque de capital, $K^{\prime}{ }_{s s}$ (bem como a do PIB, $Y^{\prime}{ }_{\text {ss }}$ ), é dada por:

$K^{\prime}{ }_{S S}=A^{\prime}+N^{\prime}$

onde $A^{\prime}$ é a taxa de crescimento da produtividade total dos fatores ampliadora do trabalho e $N^{\prime}$ é a taxa de crescimento da força de trabalho. Estimamos $A^{\prime}$ como o resíduo de uma função de produção Cobb-D ouglas com progresso técnico ampliador de trabalho, supondo um valor de 0,5 para a elasticidade do produto com respeito ao capital-em-uso ${ }^{16}$.

0 comportamento de $A^{\prime}$ assim estimado é altamente congruente com o padrão volátil de crescimento do PIB. Por causa dessa volatilidade de ano para ano, trabalharemos com uma média anual de A' para períodos representativos, quando formos discutir as épocas características de crescimento do Brasil. De uma forma ampla, duas longas ondas são sugeridas pelo comportamento de $A^{\prime}$ : uma prévia a meados dos anos 1970 - quando $A^{\prime}$ foi geralmente muito alto - e outra depois desta época - quando $A^{\prime}$ foi geralmente muito baixo. $M$ ais recentemente, isto é, depois de 1988, A' parece estar tendendo a crescer novamente. 0 comportamento de $A^{\prime}$, como veremos com mais detalhe na próxima seção, sugere que, de uma perspectiva da produtividade total dos fatores, o mergulho do crescimento brasileiro começa não na década de 1980 mas na década de 1970.

0 valor de estado estacionário de $v_{s s}$ é fácil de calcular. Simplesmente substitua-se o valor de estado estacionário de K', dado por (6), na expressão para a acumulação de capital (5) para obter:

$$
v_{s s}=\left(\delta+A^{\prime}+N^{\prime}\right) / s .(1 / p) \cdot u
$$

J untando nossas estimativas de $s(1 / p) u$ com aquelas para $A^{\prime}+N^{\prime}$ (mais $\delta$ ), calculamos os valores de $v_{S S}$. Contrariamente à sabedoria convencional dos livros-texto, $v_{s s}$ não é uma constante, mas flutua consideravelmente. Contudo, os valores calculados de $v_{s S}$ são menores do que os de v para a maior parte do período. Assim, um processo de ajustamento de longo prazo em direção a um valor estacionário mais baixo poderia também explicar o comportamento observado de v. Essa conclusão do modelo de Solow-Swan é confirmada por uma regressão de mínimos quadrados comuns de $v$ em $v_{s S}$ e em seu próprio valor defasado ${ }^{17}$. A soma dos coeficientes de $v(-1)$ e $v_{s S}$ é igual a um, como se deveria esperar de um processo de ajustamento em que $v$ converge assintoticamente para $v_{S S}{ }^{18}$. A lém disso, e de forma muito importante, o coeficiente de $v_{s s}$ indica que somente $3,6 \%$ da distância entre $v$ e $v_{s s}$ é percorrida ao longo de um ano. Isto significa que levam quase 19 anos para fechar metade do hiato entre o $v$ observado e seu cor-

\footnotetext{
${ }^{16}$ O $\mathrm{s}$ dados da força de trabalho foram extraídos dos Censos Demográficos decenais e interpolados para os demais anos supondo uma elasticidade constante (dentro de cada década) com respeito ao crescimento do estoque de capital utilizado.

${ }^{17}$ O s resultados dessa regressão podem ser vistos na versão completa deste artigo, no site da REP.

${ }^{18} \mathrm{O}$ s resíduos desta equação são estacionários mais não são ruídos brancos. Entretanto, outras especificações com um termo constante adicionado ou variáveis diferenciadas indicam que os resultados obtidos são robustos.
} 
respondente valor de equilíbrio estacionário. Esse resultado é semelhante ao das simulações numéricas da velocidade de convergência num modelo de Solow linearizado em Romer (2001). Em suas simulações, Romer estima que somente $4 \%$ da distância entre os valores observados e de estado estacionário da relação entre capital e trabalho efetivo é coberta ao longo de um ano.

$\mathrm{N}$ ossa conclusão é que qualquer das três hipóteses - ineficiências no processo de substituição de importações, uma tendência mundial de aumento da intensidade de uso do capital, e um ajustamento de longo-prazo a uma taxa de poupança mais el evada - são interpretações plausíveis para o declínio da relação produto-capital utilizado do país.

\section{HISTERESE DA CAPACIDADE OCIOSA?}

O último componente de nossa explicação para a frustração do crescimento brasileiro é um declínio no grau médio de utilização da capacidade (u). A construção de uma série para esta variável não é uma tarefa estatística fácil, particularmente porque nenhuma informação sobre ela é disponível antes de 1968; a partir de então, uma inferência pode ser feita sobre o valor da utilização da capacidade na economia como um todo a partir das taxas de utilização da capacidade na indústria ${ }^{19}$. 0 Gráfico 7 mostra o comportamento do grau estimado de capacidade ociosa na economia como um todo (1-u), de 1940 a 2002. Padrões cíclicos "normais" são indicados até o final dos anos 1970. M as, a partir do início dos anos 1980, a economia brasileira parece ser incapaz, até mesmo temporariamente, de retornar a um estado de plena utilização da capacidade.

Gráfico 7: Capacidade ociosa, 1940-2002

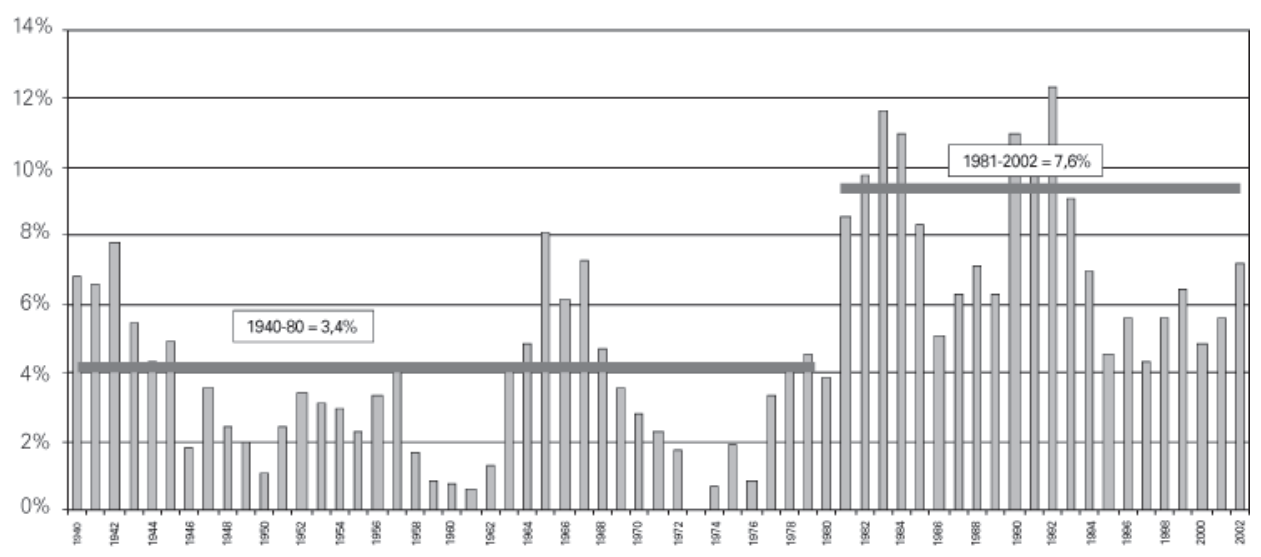

${ }^{19} \mathrm{O}$ A pêndice 2, encontrável na versão deste artigo no site da REP, provê detalhes sobre os métodos que adotamos. 
N os 40 anos anteriores a 1980, o grau médio de capacidade ociosa foi de $3,4 \%$. Depois de 1980 , ele aumentou para 7,6\%. Da mesma forma, antes de 1980, o grau mínimo de capacidade ociosa foi zero, enquanto que, depois de 1980 , ele foi de cerca de 4,4\% . N a falta de estudos adicionais, não é claro se devemos escolher a média ou o mínimo como uma estimativa da taxa "normal" de ociosidade. $M$ as ambas sugerem um aumento de mais de 4 pontos de percentagem na taxa "normal" de ociosidade depois de 1980.

Por que isso teria ocorrido? Falta de demanda ef etiva não pode ser a resposta, porque, num número de anos nesse período (por exemplo: 1986, 1989, 199596), a inflação ou os déficits externos claramente aceleraram sob a pressão de demanda doméstica excessiva. Uma hipótese possível é que estejamos subestimando o grau de ociosidade antes de 1970, porque nosso procedimento de estimação para esse perío do é muito indireto, resultando de uma inferência a partir da taxa de variação da produção industrial, e não de observação direta.

Independentemente de se aceitar ou não nosso método de estimação para 1940-68, é ainda verdade que os níveis observados de utilização de capacidade na indústria no início dos anos 1970 jamais foram alcançados a partir de 1980. De fato, foi somente no pico do "boom" de demanda provocado pelo plano R eal de estabilização (1995 e 1997) e durante a recuperação cíclica de 2000 que 0 grau relativamente baixo de utilização da capacidade industrial de 1968 foi novamente alcançado posteriormente a 1980.

Explicar o declínio sustentado do grau de utilização de capacidade após 1980 é algo que não temos como fazer aqui. M eramente em termos de tópicos de pesquisa, em primeiro lugar em nossa lista estariam as sucessivas moratórias da dívida interna e externa nos anos 1980. D epois dessas moratórias (que interromperam apenas temporariamente o crescimento da dívida pública) parece haver ocorrido um aumento substancial na taxa real de juros no país. Uma explicação possível é que a seqüência de moratórias da dívida aumentou as taxas requeridas tanto de retorno do capital como a taxa real de juros. Isto teria levado a um aumento da margem desejada de lucros sobre os custos variáveis, assim tendendo a acelerar a taxa de inflação para uma dada taxa de desemprego (ou, de forma equivalente no curto prazo, para uma dada taxa de utilização da capacidade). A implicação é que a taxa de desemprego que não acelera a inflação (ou de forma equivalente no curto prazo, a taxa "normal" de capacidade ociosa) se tornaria maior do que antes.

0 aumento do ônus dos impostos a partir do início dos anos 1990 estaria em segundo lugar na fila para explicar o aumento na capacidade ociosa. Um forte aumento na parcela do trabalho informal no emprego urbano total acompanhou esse processo ao longo da década de 1990. Uma hipótese plausível é que o aumento da cunha fiscal tenha deslocado a atividade econômica do setor formal mais produtivo para o setor informal menos produtivo, assim reduzindo o grau de utilização da capacidade no setor formal.

Em terceiro lugar, e de forma mais genérica, a Constituição de 1988, acoplada a decisões legislativas e judiciárias subseqüentes, parece haver agravado a 
precariedade do sistema de regulação econômica e, particularmente, a incerteza sobre as relações contratuais. Um ambiente jurídico menos confiável pode também haver contribuído para aumentar a volatilidade da produção e o uso "normal" da capacidade instalada.

Em resumo, nossa hipótese é que uma série de intervenções de política distorcedoras da alocação de recursos após 1980 levou a um maior grau de capacidade ociosa "normal" desde então.

\section{CONTABILIZANDO O CRESCIMENTO: UMA SÍNTESE}

Conforme salientado, na maior parte do período analisado o Brasil esteve fora do estado estacionário, com v continuamente perseguindo um volátil $v_{\mathrm{ss}}$. Também vimos que a velocidade de convergência de $v$ na direção de $v_{s s}$ é pequena. Isto justifica que na busca de uma síntese da experiência brasileira de crescimento centremos a atenção no comportamento das taxas de crescimento do estoque de capital e do PIB fora do estado estacionário. Começamos com a definição de seis períodos com aproximadamente dez anos cada, caracterizados pelas origens e conseqüências de políticas econômicas amplamente similares. Esses períodos são os seguintes:

- Prosperidade do fim de Guerra e imediato pós-Guerra: 1942-52;

- Era de JK e suas seqüelas: 1952-64;

- "M ilagre" autoritário brasileiro: 1964-74;

- Choques externos e declínio dos militares: 1974-84;

- H iperinflação: 1984-93;

- Era do Real: 1993-2002;

$\mathrm{N}$ a Tabela 1 as taxas de crescimento do estoque de capital para cada uma dessas épocas é decomposta, de acordo com a equação (5) em seus componentes u (utilização de capacidade), v (relação produto/capital-em-uso), p (preço relativo do investimento), e s (taxa de poupança).

Tabela 1: Decomposição das taxas de crescimento do estoque de capital, 1942-2002

\begin{tabular}{cccccc}
\hline Períodos & $\mathrm{K}^{\prime}$ & $\mathrm{u}$ & $\mathrm{v}$ & $\mathrm{p}$ & $\mathrm{s}$ \\
\hline $1942-52$ & 70,077 & 70,969 & 70,591 & 70,615 & 0,122 \\
\hline $1952-64$ & 0,078 & 0,975 & 0,493 & 0,632 & 0,154 \\
\hline $1964-74$ & 0,085 & 0,963 & 0,469 & 0,649 & 0,186 \\
\hline $1974-84$ & 0,078 & 0,940 & 0,408 & 0,751 & 0,222 \\
\hline $1984-93$ & 0,031 & 0,915 & 0,355 & 0,978 & 0,210 \\
\hline $1993-02$ & 0,024 & 0,943 & 0,340 & 0,993 & 0,196 \\
\hline
\end{tabular}

O s dados na tabela confirmam que o crescimento do estoque de capital avançou a taxas muito elevadas até meados dos anos 80 , com um clímax de $8,5 \%$ ao 
ano no período do "milagre" (1964-74). M as o comportamento de seus componentes mudou de forma significativa dependendo da fase considerada. A ssim, a utilização média de capacidade permaneceu em níveis el evados durante as três primeiras fases (1942 até 1974), em cerca de 0,97. Ela declinou fortemente depois disso, especialmente no período 1974-84. A relação produto/capital-em-uso (v) caiu durante toda a história, e sua tendência declinante foi também acentuada na década de 1974-84. 0 preço relativo do investimento, por sua vez, aumentou continuamente em todos os períodos, e de forma particularmente forte desde 1984.

A partir da última coluna na Tabela 1 confirmamos que a taxa de poupança (s) foi a principal fonte de dinamismo do estoque de capital até o início dos anos 1980: s aumentou substancialmente do início dos anos 1940 até 1974-84, refletindo o grande aumento da dívida externa neste último período. $\mathrm{N}$ ão fosse por isso, a taxa de crescimento do estoque de capital em 1974-84 teria sido muito mais baixa, por causa das forças de contração exercidas por menor utilização de capacidade, reduzida relação produto/capital utilizado e maiores preços do investimento. 0 colapso do crescimento do estoque de capital depois de 1984 é explicado principalmente pelo comportamento muito adverso de $p$, o preço relativo do investimento. T ambém colaboraram as quedas de u e especialmente de v, enquanto que s permaneceu praticamente inalterada. Um pequeno declínio da poupança ajuda a explicar o desempenho ruim de $K^{\prime}$ no último período na tabela (1993-2002), junto com declínios em v e em 1/p. A utilização da capacidade, por sua vez, contribuiu para aumentar $K^{\prime}$ nesse período.

Em resumo, a principal razão da depressão na acumulação de capital nos últimos vinte anos parece ter sido o aumento no preço relativo do investimento, que reduziu fortemente o poder de compra da poupança. Um exercício simples ilustra esta conclusão. Suponha-se que $p$ houvesse permanecido até $2002 \mathrm{com}$ seu valor médio no período do "milagre" (1964-74), isto é $1 / 3$ menor do que 0 valor observado no período 1984-2002. Então, tudo o mais permanecendo constante, a taxa média de crescimento do estoque de capital teria sido duas vezes maior em 1984-2002. Recorde-se que o fenômeno de um $p$ crescente foi uma peculiaridade brasileira, provavelmente relacionada ao isolamento econômico do período posterior a 1974. N ossa conclusão tentativa é, pois, que uma resposta mais inteligente aos choques econômicos dos anos 1970 teria podido evitar o declínio na acumulação de capital observado nas duas últimas décadas.

Duas decomposições alternativas do crescimento do PIB são discutidas em seguida. A primeira é de acordo com o modelo " $Y=A K$ ", cuja equação final é:

$Y^{\prime}=v^{\prime}+u^{\prime}+K^{\prime}$

onde $Y$ é o PIB, $v$ a relação produto/capital utilizado, u o grau de utilização da capacidade, e K o estoque de capital disponível - e onde o sinal (') depois de uma variável denota sua taxa logarítmica de crescimento.

O s resultados dessa decomposição são mostrados na Tabela 2, de acordo com os mesmos períodos antes identificados. Uma descoberta na Tabela 2 é que o colapso do crescimento do PIB em 1974-84 antecipou em uma década a queda da acumulação de capital, que ocorreu somente depois de 1984. Em 1974-84, 
uma utilização decrescente da capacidade instalada (após 1980) e uma relação produto/capital-em-uso rapidamente decrescente foram as responsáveis por uma taxa de crescimento do PIB menor do que a metade da taxa de crescimento do estoque de capital. A recessão de 1981-83, induzida pela crise da dívida do período, juntamente com o impulso industrializando altamente capital intensivo nos sete anos anteriores, dividem a responsabilidade por isso.

Tabela 2: Decomposição das taxas de crescimento do PIB - modelo AK, 1942-2002

\begin{tabular}{ccccc}
\hline Períodos & $\mathrm{Y}^{\prime}$ & $\mathrm{K}^{\prime}$ & $\mathrm{u}^{\prime}$ & $\mathrm{v}^{\prime}$ \\
\hline $1942-52$ & 0,069 & 0,077 & 0,005 & $-0,011$ \\
\hline $1952-64$ & 0,067 & 0,078 & $-0,001$ & $-0,008$ \\
\hline $1964-74$ & 0,088 & 0,085 & 0,004 & $-0,002$ \\
\hline $1974-84$ & 0,039 & 0,078 & $-0,011$ & $-0,025$ \\
\hline $1984-93$ & 0,025 & 0,031 & 0,002 & $-0,008$ \\
\hline $1993-02$ & 0,027 & 0,024 & 0,002 & 0,001 \\
\hline
\end{tabular}

O s dados na Tabela 2 mostram que, ainda que a causa próxima do crescimento do PIB tenha sido o crescimento do estoque de capital, mudanças na utilização da capacidade e na relação produto/capital-em-uso foram também importantes determinantes. A ssim, um dos fatores por trás do "milagre econômico brasileiro" foi um grau crescente de utilização de capacidade (u) enquanto que mudanças em v contribuíram para diminuir a taxa de crescimento desse período. Por outro lado, a pequena recuperação do crescimento em 1993-2002 foi também influenciada por um grau maior de utilização de capacidade, uma vez que a acumulação de capital continuou a cair.

O segundo enfoque para decompor o crescimento do PIB é de acordo com a função de produção tradicional de Solow -Swan, da qual a seguinte aproximação é obtida ${ }^{20}$, sob a hipótese de que a elasticidade do produto com respeito tanto ao capital quando ao trabalho efetivo é igual a 0,5:

$Y^{\prime}=(1 / v)^{\prime}+A^{\prime}+L^{\prime}$

onde $Y^{\prime}$ é a taxa de crescimento do $\mathrm{PIB}, \mathrm{A}^{\prime}$ é a taxa de progresso técnico ampliador de trabalho, L' é a taxa de crescimento do emprego, e onde $(1 / \mathrm{v})^{\prime}$ representa o aprofundamento do capital (isto é, a diferença entre o crescimento do estoque de capital em uso e o crescimento do trabal ho efetivo). A equação (9) mostra que, fora do estado estacionário, o aprofundamento do capital divide com o trabalho efetivo a explicação para o crescimento do PIB.

Antes de entrar no exercício numérico, vale a pena explorar as diferenças entre as equações (8) e (9). Em um caso [AK ], v' está contribuindo positivamente para o crescimento do PIB, enquanto que em outro [Solow-Swan] é o seu inver-

${ }^{20}$ V eja-se derivação no A pêndice 1 da versão deste artigo, disponível no site da REP. 
so, (1/v)' que tem uma contribuição positiva a fazer. A reversão de papéis não é difícil de explicar. Em (9), a variável crítica para o crescimento do PIB é a acumulação de capital. A ela precisamos adicionar as taxas de variação da produtividade de capital (isto é, v') e da utilização de capacidade (u'), para obter a taxa de crescimento do produto. Em (9), a variável crítica é o crescimento do trabaIho efetivo (A.L). A ele precisamos adicionar o aprofundamento do capital, (isto é, $\left.(1 / v)^{\prime}\right)$, ou a contribuição adicional da acumulação de capital, para obter a ta$x a$ de crescimento do PIB.

A Tabela 3 mostra os resultados da decomposição do crescimento do PIB expressa pela equação (9). A dicionamos uma última coluna para mostrar a parcela do crescimento do PIB explicada pela produtividade total dos fatores (TFP).

Tabela 3: Decomposição alternativa das taxas de crescimento do PIB modelo de Solow-Swan, 1942-2002

\begin{tabular}{cccccc}
\hline Períodos & $\mathrm{Y}^{\prime}$ & $(1 / \mathrm{v})^{\prime}$ & $\mathrm{L}^{\prime}$ & $\mathrm{A}^{\prime}$ & $\mathrm{A}^{\prime} / \mathrm{Y}^{\prime}(\%)$ \\
\hline $1942-52$ & 0,069 & 0,011 & 0,021 & 0,035 & 51,1 \\
\hline $1952-64$ & 0,067 & 0,008 & 0,025 & 0,032 & 48,1 \\
\hline $1964-74$ & 0,088 & 0,002 & 0,032 & 0,052 & 59,0 \\
\hline $1974-84$ & 0,039 & 0,026 & 0,031 & 0,017 & $-43,5$ \\
\hline $1984-93$ & 0,025 & 0,008 & 0,025 & $-0,008$ & $-32,0$ \\
\hline $1993-02$ & 0,027 & $-0,001$ & 0,016 & 0,012 & 43,1 \\
\hline
\end{tabular}

0 resultado mais importante desta tabela é enfatizar o papel crucial de $(1 / \mathrm{v})^{\prime}$ para explicar o crescimento do PIB em 1974-84: o aprofundamento do capital a uma taxa de $2,6 \%$ ao ano foi o principal fator responsável para a sustentação de uma taxa média de crescimento do PIB de 3,9\% nesse período, uma vez que 0 crescimento do trabalho efetivo $\left(A^{\prime}+L^{\prime}\right)$ foi de apenas $1,4 \%$ ao ano. $M$ esmo moderado, o crescimento do PIB na última década do regime militar somente pôde ser mantido na base de altas doses de aprofundamento do capital financiadas pela acumulação de dívida externa. A dívida externa como uma proporção do PIB aumentou para 43,1\% em 1984 vindo de 16,3\% em 1974, enquanto que a razão do serviço da dívida para as exportações de mercadorias passou de 33,4\% para 102,3\% no mesmo período (Cf. Gordon, 2002).

Tanto em 1964-1974 como em 1993-2002 a contribuição do aprofundamento do capital foi pequena ou inexistente. $M$ as isso não significa que a economia estivesse em um estado de crescimento uniforme estável nesses períodos. De fato, nossos cálculos indicam que a relação produto capital de equilíbrio flutuou bastante em ambos os períodos, mas sem tendência definida. Deste modo, a relação produtocapital observada esteve perseguindo um alvo móvel, que se moveu para cima e para baixo, deixando a impressão de que a economia estava estabilizada, quando de fato ela estava experimentando fortes flutuações, embora sem uma tendência definida. 
A importância de mudanças na PTF variou substancialmente através do tempo, atingindo valores negativos tanto durante o período dos choques externos (1974-84) - quando uma surpreendente taxa de declínio de 1,7\% ao ano foi observada - e nos anos da hiperinflação (1984-93). N os demais períodos, a TFP representou uma parcela substancial do crescimento do PIB, com um máximo de $60 \%$ nos anos do "milagre". $\mathrm{N}$ a era do Presidente Cardoso, não fora por uma recuperação de $A^{\prime}$ ( $1,2 \%$ ao ano, contra $-0,8 \%$ no período anterior), o crescimento do PIB teria sido de apenas $1,5 \%$ ao ano, ao invés dos observados $2,7 \%$. Assim, de uma perspectiva de períodos decenais, as duas "décadas perdidas" para a PTF não foram as décadas de 1980 e 1990, mas sim, 1974-84 e 1984-93 a longa e atormentada transição da ditadura para a democracia, caracterizada pelo acúmulo da dívida externa e a hiperinflação.

Esse resultado depende criticamente de considerar-se o período 1974-84 como um todo, o que implica visualizar a crise de 1980-83 como uma parte integral da chamada marcha forçada do perío do G eisel. Uma alternativa seria considerar o período menor de 1974-80 de forma isolada, e o período mais longo de 1980-93 como um só bloco. 0 aprofundamento do capital medido por (1/v)' caracterizou ambos os períodos, procedendo a 2,0\% ao ano em 1974-80 e a 1,6\% ao ano em 1980-93. M as o colapso tanto do crescimento do PIB como do progresso técnico ocorreram integralmente dentro do segundo período. $O$ crescimento anual do PIB em 1974-80 foi menor do que no "milagre", mas ainda assim de respeitáveis $6,9 \%$ ao ano. 0 progresso técnico também declinou fortemente, mas ainda foi positivo a uma taxa de $0,9 \%$ por cento por ano. Em contraste, 0 crescimento médio do PIB em 1980-93 foi somente 1,6\% e a mudança técnica foi fortemente negativa, a - 2,3\% por ano. Assim, de um ponto de vista estatístico, os períodos perdidos de crescimento brasileiro não foram duas décadas inteiras, mas os treze anos entre 1980 e 1993.

$\mathrm{N}$ o período do Real, a contribuição do trabalho bruto ( $\left.L^{\prime}\right)$ é muito pequena - um fato relacionado não ao declínio do crescimento da força de trabalho, mas a uma reduzida absorção de mão-de-obra. U ma explicação possível para isso é que o ritmo de acumulação de capital não acompanhou o do progresso técnico, gerando assim menos oportunidades de emprego a um dado custo do trabalho.

\section{CON CLUSÃO: SOBRE O POTEN CIAL DE CRESCIMENTO BRASILEIRO}

As conclusões sobre o potencial de crescimento do Brasil variam, dependendo do modelo usado. N uma perspectiva do modelo AK, e presumindo que o grau de utilização de capacidade (u) e a relação produto/capital-em-uso (v) se mantenham constantes, o crescimento do PIB pode ser aproximado pelo crescimento do estoque de capital ( $\left.K^{\prime}\right)$. Este pode ser escrito na forma da equação (5) como sendo:

$$
\mathrm{K}^{\prime}=\mathrm{s}(1 / \mathrm{p}) \mathrm{uv}-\delta
$$


Valores correntes para as variáveis do lado direito são aproximadamente como se segue: taxa de poupança total $(s)=0,19$; preço relativo do investimento $(p)=1,0$; grau médio de utilização da capacidade $(u)=0,93$; produtividade do capital $(v)=0,34$; e taxa de depreciação do estoque de capital (?) =0,039. Inserindo esses valores na equação anterior, resulta: $\mathrm{K}^{\prime}=2,1 \%$. Tal seria o potencial atual de crescimento brasileiro de acordo com o modelo AK.

Da perspectiva de estado estacionário do modelo de Solow, o crescimento do PIB é restrito pela soma do crescimento da força de trabalho N ' (correntemente de $2,1 \%$ ao ano) com a taxa de crescimento da produtividade total dos fatores $A^{\prime}$, a qual foi $2,2 \%$ em média no período 2000-2002. Isto gera uma taxa potencial de crescimento do PIB de 4,3\%. A partir do fato de que a taxa de crescimento do estoque de capital ( $K$ ') é menor do que a taxa de crescimento do trabalho efetivo $\left(A^{\prime}+N^{\prime}\right)$ segue-se - num contexto de Solow-Swan - que a taxa de crescimento de curto prazo do produto é menor do que seu valor de estado estacionário. Supondo $?=0,5$ e que u seja constante, bem como que $L^{\prime}=N^{\prime}$, esta taxa de crescimento de curto prazo do PIB pode ser obtida como uma média simples da taxa de crescimento de 4,3\% do trabalho ef etivo e da taxa de crescimento de $2,1 \%$ do estoque de capital - isto é, 3,2\% ao ano. Esta seria a taxa potencial de crescimento de curto prazo do PIB de acordo com o modelo de Solow-Swan.

Comecemos do limite inferior dessas alternativas, supondo $v$ constante. $\mathrm{N}$ este caso, o crescimento potencial de curto prazo do PIB é limitado pela formação de capital (como no modelo AK), isto é, 2,1\%. Considere-se o grau correntemente observado de utilização de capacidade $u=0,93$. $N$ ossos resultados sugerem um grau médio de utilização da capacidade de 0,95 num período recente como 1995-2000. Isto quer dizer que, na medida em que a inflação convirja para a meta de longo prazo do governo, haverá espaço para um moderado alívio de crescimento comandado pela demanda. De acordo com a equação (8), aumentando u de 0,93 para 0,95 eleva-se a taxa de crescimento de curto prazo do PIB em aproximadamente 2 pontos de percentagem. $M$ as esse é um efeito "de uma vez por todas" se a acumulação de capital não variar. Entretanto, se tal nível mais elevado de utilização $u=0,95$ puder ser sustentado de forma permanente, então, de acordo com a equação (5) isso permitiria uma muito modesta el evação da taxa de crescimento do capital para 2,2\% (em comparação com os anteriormente estimados 2,1\%).

$M$ ais eficazes seriam políticas que lidassem com o preço relativo do investimento, p. Tais políticas seriam consistentes com os resultados empíricos em Jones (1994) sobre a relação negativa entre crescimento econômico e preço relativo do investimento, bem como com a advertência de Rodrik (1999, p. 27), de que " como os países em desenvolvimento não têm uma vantagem comparativa na produção de bens de capital, restrições comerciais em tais indústrias tendem a ser prejudiciais para o crescimento. A proteção comercial aumenta o preço relativo dos bens de capital e reduz o nível do investimento real que é alcançável para um dado nível de poupança". Introduzir contestação de mercados parece ser um curso de ação que faz sentido aqui: uma maior abertura para a importação 
de bens de capital (por exemplo, abolindo os remanescentes da abominável "Iei da informática" de 1984), junto com políticas pró-concorrência, poderia ter um impacto importante. Assim, por exemplo, se fosse possível fazer $p$ retornar para os valores observados em meados dos anos $1980(p=0,8)$, a taxa de crescimento do estoque de capital aumentaria dos 2,2\% anteriormente calculados para 3,8\%, tudo o mais permanecendo constante. $N$ ote-se que isso implica que a taxa de poupança a preços constantes, $s(1 / p)$, aumentaria de 4,9 pontos percentuais.

Fica faltando a taxa de poupança nominal, s, que tem se situado em torno de $19 \%$ do PIB nas duas últimas décadas, com a peculiar exceção de valores bem maiores durante os anos da hiperinflação. Uma maior taxa doméstica de poupança pode ser alcançada no médio e longo prazos, na medida em que medidas de construção de confiança aumentem a poupança privada e em que os desequilíbrios nas contas do setor público sejam tratados de uma forma duradoura.

Esses exercícios indicam não ser difícil imaginar cursos de ação para fazer a acumulação de capital mover-se para 4,2\% ao ano, ponto em que ela encontraria a restrição de crescimento equilibrado do modelo de Solow. Para ir além disso, modos e maneiras de acelerar a taxa de progresso técnico ( $\left.A^{\prime}\right)$ deveriam ser considerados. $\mathrm{N}$ osso texto tem pouco a oferecer nessa direção. $\mathrm{M}$ as a literatura corrente (por exemplo, Pinheiro, 2003) está cheia de sugestões, evolvendo maior taxa de investimento em capital humano, reforma fiscal, aumento do comércio exterior, etc.

Uma palavra final de cuidado é pertinente. $N$ este texto, seguimos fielmente os comandos dos modelos AK e de Solow, assim focando a atenção sobre a poupança e o progresso técnico como determinantes alternativos, mas últimos, do crescimento do PIB. Ignoramos os limites impostos por uma função autônoma de investimento, bem como restrições de divisas possivelmente redutoras do potencial de crescimento brasileiro. Q uanto à primeira, é nossa convicção que a propensão do setor privado a investir não deve representar um impedimento para a taxa de crescimento do país, desde que sejam superadas as dúvidas remanescentes sobre a capacidade do Presidente Lula de sustentar políticas econômicas sensatas.

A restrição de divisas é uma matéria mais delicada: alguns podem argüir que a consolidação fiscal junto com uma taxa de câmbio flutuante são suficientes para superar dificuldades nessa área. Somos céticos: até que o país demonstre ser capaz de desenvolver um mercado de capitais de longo prazo localmente, a necessidade de empréstimos externos em dólares não deve desaparecer. 0 ataque às incertezas jurisdicionais que correntemente impedem o desenvolvimento de um mercado de capitais de longo prazo localmente parece ser a maneira de resolver esse problema. Com essa observação, deixamos o importante tópico da incerteza jurisdicional para ser considerado em outro texto (cf. P. Arida, E. Bacha e A. L. Resende, 2005). 


\section{REFERÊN CIAS BIBLIOGRÁFICAS}

ARIDA, P., BACH A, E. e RESEN DE, A. L. (2005) “Credit, interest, and jurisdictional uncertainty: conjectures on the case of Brazil", em F. Giavazzi e I. Goldfajn (orgs.), Inflation Targeting, D ebt, and the Brazilian Experience. M IT Press, Cambridge, M A.

ARROW, K. (1962) "The economic implications of learning by doing". Review of Economic Studies 29, 155-173.

BERN AN KE, B. e GURKAYN AK, R. (2001) “Is growth exogenous? Taking M ankiw, Romer, and Weil seriously". N BER Working Paper 8365, Julho.

BO N ELLI, R. e FON SECA, R. (1998) "Ganhos de produtividade e de eficiência: novos resultados para a economia brasileira". Pesquisa e Planejamento E conômico 28, № 2. IPEA, R io de Janeiro.

BUGARIN , M. S., ELLERY Jr., R., GOMES, V. eTEIXEIRA, A. (2003) "The Brazilian depression in the 1980s and 1990s". Universidade de Brasília, Brasília.

CARNEIRO, D. e WER NECK, R. (1993) "O bstacles to investment resumption in Brazil", em E. Bacha (org.), Savings and Investment R equirements for $\mathrm{G}$ rowth Resumption in $\mathrm{L}$ atin A merica. W ashington, DC: Inter-A merican D evelopment Bank/J ohns H opkins U. Press, Washington, DC, pp. 67-108.

GOM ES, V., PESSO A, S. e VELOSO , F. (2003) "Evolução da produtividade total dos fatores na economia brasileira: uma análise comparativa". Pesquisa e Planejamento E conômico v. 33, no 3. IPEA, Rio de Janeiro.

GORDON, L. (2002) A Segunda Chance do Brasil. Editora SEN AC, São Paulo.

HEST ON , A., SUM M ERS, R. e ATEN , B. (2002) "Penn-World Table Versão 6.1". Center for International Comparisons, University of Pennsylvania.

IBGE (1990) Estatísticas H istóricas do Brasil - 1950-1989. Fundação Instituto Brasileiro de Geografia e Estatística, Rio de Janeiro.

JONES, C. I. (1994) "Economic growth and the relative price of capital". Journal of M onetary E conomics 34, pp. 359-382.

M ORANDI, L. e REIS, E., a sair. "Estimativa do estoque de capital fixo - Brasil, 1950-2000". Texto para Discussão, IPEA, Rio de Janeiro.

PIN HEIRO, A.C., GILL, I.S., SERVEN, L. e THOM AS, M .R. (2001) Brazilian economic growth, 1900-2000: lessons and policy implications. World Bank, Washington, DC.

PIN HEIRO, A.C. (2003) “U ma agenda pós-liberal de desenvolvimento para o Brasil”. Série Seminários, IPEA, Rio de Janeiro.

RODRIK, D. (1999) The N ew G lobal E conomy and D eveloping Countries: M aking O penness W ork. O verseas Development Council, Washington, DC.

ROM ER, D. (2001) Advanced M acroeconomics. M cGraw Hill, 2a. edição.

\section{APÊNDICE 1: OS M ODELOSDE CRESCIMENTO "Y $=A K "$ E DE SOLOW-SWAN}

O modelo " $Y=A K$ ", como apresentado em Bernanke e Gurkaynak (2001), parte de uma função de produção neoclássica da forma: 
$Y=(U K) \alpha(\tilde{A} h L) 1-\alpha$

onde $Y=P I B$ GDP

$u=$ grau de utilização da capacidade

$\mathrm{K}$ = estoque real de capital

$\tilde{A}=$ fator tecnológico exógeno

$\mathrm{h}=$ fator de habilidade ampliador de trabalho (labor-augmenting skill factor)

$\mathrm{L}=$ emprego

$\alpha=$ elasticidade do produto em relação ao capital utilizado

$1-\alpha=$ elasticidade do produto em relação ao trabalho efetivo (Ã hL)

Seguindo o clássico artigo em que é exposta a noção do learning by doing, de Kenneth Arrow (1962), Bernanke e Gurkaynak postulam que as habilidades dos trabalhadores são proporcionais à relação entre capital utilizado e trabalho, isto é, $h=u . K / L$. N esse caso a função de produção pode ser simplificada para:

$\mathrm{Y}=\mathrm{v} . \mathrm{u} . \mathrm{K}$,

onde $v=\tilde{A} 1-\alpha$

A equação (1.2) pode ser decomposta, em termos de taxas de variação, aproximadamente em:

$$
Y^{\prime}=v^{\prime}+u^{\prime}+K^{\prime}
$$

onde o símbolo de apostrofe (') após cada variável denota sua taxa logarítmica de crescimento.

0 modelo de Solow-Swan parte de uma formulação mais tradicional da função de produção neoclássica:

$Y=(u . K) \alpha(A . L) 1-\alpha$

onde supõe-se que a produtividade total dos fatores (A) seja ampliadora de trabalho (labor augmenting). Para aplicação empírica, supusemos também que $\alpha=0,5$. Esse conveniente valor é consistente com a participação da remuneração do capital nas $\mathrm{Contas} \mathrm{N}$ acionais do Brasil e, além disso, reflete a elevada concentração de renda do país relativamente a outros países. Estudos recentes da experiência de crescimento brasileira utilizaram valores de ? no intervalo de 0,35 a 0,50 (ver Pinheiro et al., 2001; Bugarin et al., 2003; e Gomes et al., 2003). A adoção de valores nesse intervalo não alteraria nossas conclusões. Com $\alpha=0,5$ a equação (1.4), reescrita para expressar o crescimento do PIB, torna-se:

$$
Y^{\prime}=0,5\left(u^{\prime}+K^{\prime}+A^{\prime}+L^{\prime}\right)
$$

Essa equação nos informa que no modelo de Solow-Swan, após corrigir para variações na utilização de capacidade, a acumulação de capital $\left(K^{\prime}\right)$ divide com 0 crescimento do trabalho efetivo $\left(A^{\prime}+L^{\prime}\right)$ a explicação pelo crescimento do PIB.

$\mathrm{N}$ ote-se que (1.4) pode ser reescrito como:

$Y=(1 / v) \alpha / 1-\alpha($ A.L $)$

onde $1 / v=u . K / Y=($ u.K/A.L) $1-\alpha$

A equação (1.6) tem sido muito usada na literatura recente para explicar diferenças de níveis de renda entre países (vide Romer, 2001, págs. 138-140). Essa equação "explica" o nível do produto agregado em termos do trabalho ef etivo (A.L) ajustado por um fator que varia com o tempo (1/v). Este fator é proporcional à relação entre o capital utilizado e o trabalho efetivo, como se vê em (1.7). 
De (1.6) deduz-se a seguinte aproximação para uma decomposição do crescimento, supondo, como antes, que $\alpha=0,5$ :

$$
Y^{\prime}=(1 / v)^{\prime}+A^{\prime}+L^{\prime}
$$

Como se pode inferir de (1.7), (1/v)' representa o aprofundamento do capital - isto é, a diferença entre as taxas de crescimento do capital utilizado e do trabalho efetivo. A equação (1.8) mostra que o aprofundamento do capital divide com o crescimento do trabalho efetivo a explicação pelo crescimento do PIB. $N$ ote-se que no estado estacionário $(1 / \mathrm{v})^{\prime}$ é constante e, portanto, o crescimento do PIB depende apenas do crescimento do trabalho efetivo. 